\title{
Inteligências múltiplas e autoria docente na pro- dução de audiovisuais interativos
}

Ismênia Mangueira Soares

Edna Gusmão de Góes Brennand

Universidade Federal da Paraíba

\section{Resumo}

Este artigo discute resultados de pesquisa desenvolvida sobre autoria docente e interatividade em audiovisuais educativos. Descreve a construção de um modelo conceitual com base na Teoria das Inteligências Múltiplas. Apresenta uma ferramenta de autoria para inserir interatividade em conteúdos audiovisuais denominada MARKER. Analisa o processo de autoria na construção de conteúdos educacionais para veiculação em Televisão Digital Interativa por docentes do ensino superior. Apresenta resultados de três protótipos reestruturados e testados pelos docentes. Registra a emergência de novas habilidades dos autores para usar o potencial dos recursos hipermídia na educação.

Palavras-chave: Inteligências múltiplas. Ferramenta de autoria MARKER. Hipermídia na educação.

\section{Multiple intelligences and teaching authorship in the production of interactive audiovisual}

\section{Abstract}

This article is included in the discussions on cultural practices in Youth and Adult Education and aimed to understanding how to place the cultural practices of the subjects "thinkers and practitioners" in living "places and times" and how they relate to the manifest cultural practices in everyday school life. It is based on Alves (2003), Bakhtin (1992) and Certeau $(2011$ 1, 2012, 2013) studies. The conclusion pointed to the existence of two cultural practices (in)visualized in the Valley of Reginaldo region: the practice of the "Meeting", as reinvented event, and the "Boi Leão" practice, as a resistance event - establishing itself as the starting point for the production of knowledge and sense at school, about the problems and dialogues established by a group or people within interacting. Keywords: Multiple Intelligences. MARKER authoring tool. Hypermedia in education. 


\section{Las inteligencias múltiples y la autoría de enseñanza en la produc- ción de audiovisual interactiva}

\section{Resumen}

Analiza los resultados de investigación sobre la autoría docente y la interactividad en contenidos audiovisuales educativos. Describe la construcción de un modelo conceptual basado en la Teoría de las Inteligencias Múltiples que genera un software de apoyo para la inserción de mecanismos de interactividad en los textos audiovisuales. Presenta la herramienta de edición llamada MARKER producida en el grupo de investigación Cultura Digital y Educación. Analiza el proceso de autoría en la construcción de contenidos educativos para Televisión Digital Interactiva para servir a los profesores de educación superior. Presenta los resultados de tres prototipos reestructurados y probados por los profesores. Se registra la aparición de nuevas habilidades de los autores al utilizar el potencial de los recursos hipermedia en educación. Palabras clave: Inteligencias múltiples. Herramienta de edición MARKER. Ccontenidos educativos para Televisión Digital Interactiva.

\section{Introdução}

Nas últimas décadas, não obstante os avanços científicos e tecnológicos e do uso intensivo das tecnologias digitais no Brasil, ainda prevalece um modelo educativo que privilegia o uso da inteligência lógico-matemática. Mesmo assim, os estudos vêm assinalando as mudanças cognitivas da nova geração que nasceu no decorrer desse processo.

O uso das tecnologias digitais no cotidiano das pessoas está propiciando o desenvolver de formas diferentes de aprender oportunizando espaços para novos comportamentos e aprendizagens e modificando as relações humanas pela emergência de redes de colaboração entre indivíduos e grupos sociais. Destaca-se um panorama da era das redes:

[...] a sociedade passou a presenciar a convergência de aplicações nas áreas da eletrônica digital, das telecomunicações e da informática e, por consequência, os grandes avanços nos meios (e modos) de os indivíduos se informarem e se comunicarem (ALMEIDA; BRENNAD, 2011 , p. 177). 
A convergência tecnológica, ao integrar redes de telecomunicações, captura e difunde informações, fornecendo a seus usuários informações e aplicações em qualquer lugar, de qualquer rede, por qualquer canal de comunicação, ou seja, ubiquidade, mobilidade e interatividade. Integrar vídeo, voz, dados e imagem mediante técnicas avançadas de integração de sistemas computacionais distribuídos e sistemas de telecomunicação, dá transparência ao usuário, possibilitando, além da mobilidade, a portabilidade de aplicações e conteúdos. A interoperabilidade entre plataformas e operadores propicia maior interconectividade. Esses avanços são responsáveis por: descentralizar os sistemas de informação e do processamento; estabelecer a comunicação entre diversos sistemas de informação multiplataformas; desenvolver sistemas e padrões abertos; e impor modificações em todas as áreas do conhecimento, especialmente na educação. Independentemente de onde estejamos fisicamente, estamos contribuindo com essas mudanças (ALMEIDA; BRENNAND, 20111 .

Segundo Lévy (1998, p. 183), o espaço do saber nasce no intelectual coletivo representado pela conexão, deslocamento e transformações inerentes às sociedades, qualificando, obviamente, a espécie humana: "[...] 90 todos os saberes do intelectual coletivo exprimem devires singulares, e esses devires compõem mundos." Para o autor Levy (1998, p. 69) "[...] cada um, a todo instante, contribui para o processo da inteligência coletiva".

As tecnologias reorganizam caminhos possíveis para o conhecimento, redirecionam os sistemas cognitivos humanos, consequentemente, o papel do ato educativo.

A competência técnica não mais se restringe ao domínio de conteúdos específicos de 'disciplinas' específicas. É nessa perspectiva das novas matrizes curriculares que o ensino de conteúdos específicos precisa estar articulado às múltiplas conexões descentralizadas, ou seja, apoiado em perspectivas arvorecentes e transdisciplinares do ciberespaço (BRENNAND, 2011 , p. 35).

Léry (1997) destaca que a linguagem digital está inserida num novo processo de alfabetização. Nesse contexto, enfatiza-se o papel dos educadores visando à criação de projetos inovadores na escola, em todos os níveis de ensino, para que a população em geral tenha acesso à rede digital. Freire (1985) afirma que a sociedade do conhecimento possibilita um grande 
encontro entre as linguagens oral, escrita e digital. Pretto (2009) vai argumentar que a juventude, de mera consumidora de informações, passa à condição de intensa produtora de culturas e conhecimentos. Para ele, essa geração, nascida na era digital, tem outra forma de se relacionar com as tecnologias e com o mundo.

Considerando esses autores, o atual contexto educacional não pode prescindir da utilização dos recursos midiáticos disponíveis. $\bigcirc$ fácil acesso às redes de comunicação afeta a atividade educativa cujos pressupostos ainda estão balizados no contexto familiar e cultural. As trocas feitas pelos aprendentes nas redes sociais modifica a sua socialização, promovendo mudanças no processo de construção de sua identidade, ambiente escolar, além da facilidade com que se integra às redes sociais.

Compreender as implicações da convergência digital para a formação docente se traduz na necessidade de desenvolver práticas educativas; assim, é possível que o conhecimento pedagógico esteja aliado ao conhecimento técnico, tornando o docente capaz de fazer escolhas metodológicas e de estratégias de ensino-aprendizagem diferenciadas, adequando-se às situações de aprendizagens do cotidiano das novas gerações que usam intensivamente as tecnologias digitais para aprender. Essa assertiva justifica a pesquisa desenvolvida, pautando um processo de autoria docente, além da integração de conteúdos, possibilitando, porém, que conteúdos sejam visitados de diferentes formas, com potencial para facilitar a aprendizagem. Trazemos um processo de autoria "[...] como um atributo (qualidade), uma referência à responsabilidade autoral em relação à sua produção material (por exemplo: artefatos tecnológicos) ou imaterial (por exemplo: ideias e modelos teóricos)" (KAPITANGO-A-SAMBA, 2013 , p. 95.).

Em um primeiro momento, o processo de autoria docente levou em consideração as relações entre cultura digital e educação. Os objetivos foram direcionados para compreender como os docentes no ensino superior desenvolviam suas competências para o uso de mídias digitais no processo ensino-aprendizagem e quais abordagens lógicas, epistemológicas e didáticas eram utilizadas para desenvolver atividades de aprendizagem que envolviam o uso de tecnologias digitais. Em um segundo momento, estudos teóricos anteriores desenvolvidos no Grupo de Pesquisa Cultura Digital e Educação foram acionados na busca de responder às inquietações iniciais e definir as linhas epistemológicas do presente estudo. 


\section{Âncoras Iniciais}

A construção do modelo conceitual foi, inicialmente, planejada considerando os resultados de pesquisas anteriores desenvolvidas pelo grupo de pesquisa Cultura Digital e Educação, com ênfase nos resultados da Tese de Borges (2010) que desenvolveu uma pesquisa-ação para produção de conteúdos digitais com crianças de 7-9 anos de uma escola pública do ensino fundamental. Nesse estudo, a Teoria das Inteligências Múltiplas forneceu bases inovadoras para pensar processos educativos mediados por tecnologias digitais, o que motivou sua utilização para pensar, agora, o universo da docência. Novos estudos foram efetivados com uma nova exploração do acervo de Gardner o que permitiu criar e estabelecer novas conexões com o tema. $\bigcirc$ ponto de partida para a investigação foi fundamentado na possibilidade de produção e disponibilização de conteúdos educativos audiovisuais interativos, com base na ação reflexiva encontrada na pedagogia da compreensão de Gardner (2000).

Construir o modelo conceitual ancorado na Teoria das Inteligências Múltiplas de Gardner (2000), em que a capacidade de resolver problemas

92 pudesse permitir ao docente a autoria de conteúdos educativos interativos que pudessem ser veiculados através da Televisão Digital Interativa, foi o foco da pesquisa. Considerando que não existe um conjunto de estratégias de ensino que funcione bem para todos as pessoas, indagamos se a construção de um modelo, que, ao ser utilizado pelo docente, poderia acionar outras estratégias e momentos diferentes de aprendizagem. A hipótese inicial é que, ao trabalhar com conteúdos educativos capazes de potencializar determinadas inteligências no aprendente, o docente estaria the oferecendo a oportunidade de ampliar o seu potencial cognitivo em relação a determinadas inteligências. Esse cenário é intrínseco à pedagogia da compreensão, apresentada por Gardner em sua Teoria (2000).

Tendo em vista um grande acervo de conteúdos educativos audiovisuais produzidos pelo Grupo de Pesquisa, e com a devida autorização dos autores, escolhemos, inicialmente, para análise e implementação da interatividade, três videoaulas produzidas: primeiro, para o curso de Licenciatura Plena em Pedagogia a videoaula "Viva a Natureza Viva", que foi utilizada para a construção da aplicação interativa X; segundo, para Curso Lato Sensu do Projeto Africanidade "Interdiciplinaridade", que foi utilizada para a construção 
da aplicação interativa Y. A terceira videoaula veio do acervo do Mestrado Profissional em Gestão de Organizações Aprendentes intitulada "Inovar - Desafio Contemporâneo das Organizações", que foi utilizada para a construção da aplicação interativa Z. Todos foram produzidos pela Universidade Federal da Paraíba - UFPB.

Trabalhamos com a definição de aprendizagem trazida por Gardner (2000) como sendo um método que uma pessoa usa para adquirir conhecimento. Cada indivíduo aprende de modo pessoal e único. Entendemos que os aprendentes percorrem diferentes abordagens ou caminhos que cada um pode traçar para si mesmo, por isso, acreditávamos ser possível desenvolver estratégias de ensino-aprendizagem, apropriadas às suas perspectivas e especificidades nos campos cognitivos, emocionais e cinestésicos e inteligências inter-relacionadas. A estimulação das conexões neurais pode ser fortalecida a partir da interatividade apresentada pelo conteúdo educativo audiovisual, construído a partir de uma intervenção pedagógica de qualidade e dos estados mentais, provenientes de padrões de atividade neural. Ao longo da pesquisa, buscamos estratégias de compreensão de como ativar e valorizar as múltiplas inteligências dos aprendentes e, que esse processo pudesse ser visualizado através de um modelo conceitual. O modelo gerou um software implementado para produzir conteúdos interativos a serem veiculados em ambientes multiplataforma (TV, Web e dispositivos móveis).

$\bigcirc$ processo de produção de conteúdos educativos foi estudado e revisado utilizando-se a ferramenta desenvolvida com base na Teoria das Inteligências Múltiplas de Gardner (2000). Com base nesse contexto, o percurso do trabalho não foi linear ou preestabelecido, mas explorado no sentido de caracterizar melhor o problema e buscar alternativas à medida que os conteúdos educacionais foram sendo delineados à luz da TIM (GARDNER, 2000|. Buscamos, com base nas interações estabelecidas com os conteúdos educacionais construídos e nas reflexões trazidas das análises e ressignificações advindas desse processo, tornar os conteúdos educativos interativos com capacidades e características pedagógicas, capazes de acionar as competências humanas. Esse contexto trouxe reflexões sobre o que seja autoria no espaço virtual. Uma delas é que se a ressignificação de conteúdos passa pela reelaboração de conhecimentos preestabelecidos, a autoria dos conteúdos ressignificados passa a ser entendida como processo coletivo, não constituindo mais uma obra exclusiva. A ferramenta de autoria, segundo Leffa, 12006, p. 
189), "[...] é um programa de computador usado para produção de arquivos digitais, geralmente incluindo texto escrito, imagem, som e vídeo". O docente, no caso desta pesquisa, precisa se deparar com uma interface amigável para construir, com rapidez, um determinado conteúdo.

software ou ferramenta de autoria foi construído para validar o modelo conceitual. Tornou-se uma ferramenta rica do ponto de vista pedagógico e efetiva para que o docente pudesse ressignificar conteúdos audiovisuais com recursos interativos, desafiando-o a perceber o aprendente como ser único que carece de alternativas, capazes de estimular o seu potencial cognitivo e, assim, adquirir novos conhecimentos. Assim, implementamos a ferramenta MARKER (Figura 1) no sentido de validar o modelo para criação de conteúdos interativos. Uma das funcionalidades da ferramenta é a execução do vídeo de origem, para que o docente identifique os momentos de inserção do conteúdo complementar; o player para execução do vídeo suporta diferentes formatos de vídeo, desde alguns mais antigos como o Audio Interchange File Format AIFF até formatos mais recentes como MPEG4 ou Audio Video Interleave - AVI.

Figura 1

\section{Interface da Ferramenta MARKER}

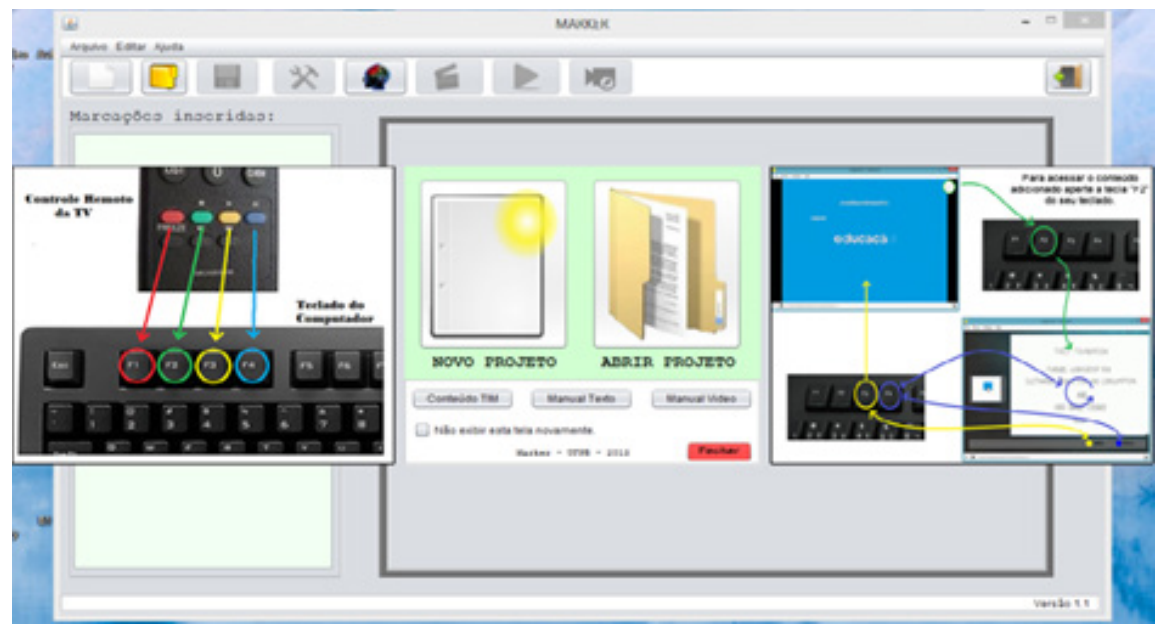

Fonte | Os autores

Essa ferramenta oportuniza ao docente estabelecer conexões com outros conteúdos considerados essenciais à aprendizagem, para criar âncoras 
estimuladoras de interatividade. $\bigcirc$ modelo conceitual foi criado com base na necessidade do docente e nos requisitos identificados para a construção dos conteúdos interativos. A primeira versão do modelo conceitual (Figura 2) surgiu, concomitantemente, com o levantamento dos requisitos para a construção da ferramenta MARKER. $\bigcirc$ modelo foi se fortalecendo à medida que versões da ferramenta iam consolidando o próprio modelo, num movimento interativo. Utilizamos uma ferramenta computacional formal de abstração e generalização com a finalidade de prever e observar as tendências do que é possível transformar, da realidade, em soluções que possam ser interpretadas na linguagem usual. $\bigcirc$ primeiro passo na construção do modelo foi a identificação das categorias basilares da TIM a serem disponibilizadas na ferramenta. Escolhemos, assim, trabalhar com sete categorias basilares, possíveis de ser representadas através de ícones já consolidados, representativos das inteligências múltiplas, propostos por Zandomeneghi (2005). No tratamento dos resultados, as inferências e interpretações foram feitas com base nas categorias basilares escolhidas (GARDNER, 2000): inteligência linguística; inteligência lógico-matemática; inteligência interpessoal; inteligência intrapessoal; inteligência espacial; inteligência corporal-cinestésica; inteligência musical.

Figura 2

Modelo Conceitual

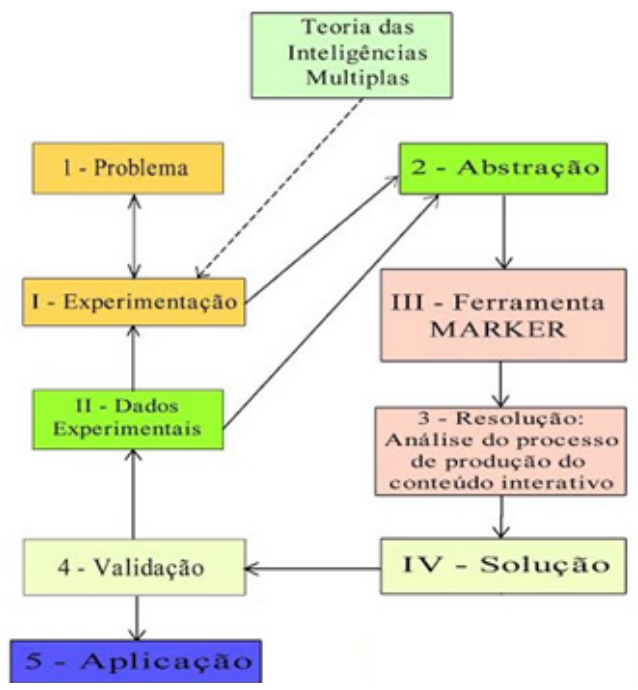

Fonte | Os autores 


\section{Bases conceituais}

A palavra inteligência traduz a faculdade de entender, pensar, raciocinar e interpretar. A capacidade do nosso cérebro em compreender alguma coisa, segundo Gardner (1995), passa pela escolha de caminhos que nos levem à compreensão. Gardner afirma que poderíamos discutir o conceito de inteligência como manifestação de compromisso entre dois componentes:

[...] (a) os indivíduos, que são capazes de utilizar sua série de competências em vários domínios de conhecimento; (b) as sociedades, que estimulam o desenvolvimento do indivíduo através das oportunidades que proporcionam, das instituições que sustentam e dos sistemas de valores que promovem (GARDNER, 1995, p. 201).

Para o autor, as competências individuais representam, apenas, um aspecto da inteligência que, por sua vez, precisa de estruturas e instituições sociais para o desenvolvimento das competências: "Nessa estrutura, a inteligência se torna um construto flexível, culturalmente dependente" (GARDNER, 1995, p. 2011.

Para Gardner (1995), as definições de inteligência estão moldadas pela época, lugar e cultura em que elas evoluem. $\bigcirc$ autor acrescenta que, embora tenhamos conceitos de inteligência diferentes de acordo com as sociedades, uma mesma matriz de forças influencia esta dinâmica: os domínios de conhecimento para a sobrevivência da cultura, os valores inseridos na cultura e o sistema educacional que instrui e estimula as várias competências dos indivíduos. Assim, Gardner (1995, p. 197 e 194) apresenta um conceito de inteligência que vai além da mente humana, contemplando a sociedade em que essas mentes devem operar: "[...] cada mente tem seu contexto socioeconômico específico [...]" e "[...] cada mente compartilha várias extensões humanas e não humanas". Essas configurações, segundo Gardner (1995), precisam ser contempladas no ambiente educacional, com instrumentos de avaliação adequados, com melhor compreensão do papel do meio cultural e de seus artefatos.

A TIM se insere na abordagem cognitivista e, como tal, Gardner conceitua inteligência da seguinte forma:

[... ] a inteligência se definiria como um mecanismo neural ou um sistema computacional que está geneticamente programado para ser 
ativado ou 'disparado' por determinados tipos de informação que se apresentam interna ou externamente (GARDNER, 2000, p. 64).

Para Gardner (2000, p. 47), as inteligências se constituem de "[...] um potencial biopsicológico para processar informações que pode ser ativado num cenário cultural para solucionar problemas ou criar produtos que sejam valorizados numa cultura". As inteligências são inatas ao ser humano, podendo ser estimuladas pelo ambiente onde ele está inserido. A competência de fazer uso dessas inteligências torna-se evidente quando realizamos uma tarefa. Segundo Gardner (2000), a noção de competência surge quando um problema é proposto. Ou seja, a operacionalização do uso de nossa inteligência se traduz no grau de competência para resolver com eficiência um determinado problema. A competência cognitiva humana pode ser descrita através das capacidades, talentos ou habilidades mentais que chamamos de inteligência (GARDNER, 1995). Perceber que cada ser humano possui múltiplas inteligências traz implicações importantes para a esfera educacional.

Segundo Gardner (1995), as manifestações de inteligência estão relacionadas à cultura a que pertence o indivíduo e essa percepção nos ajuda a ver onde e como é possível perceber essas manifestações e como potencializá-las.

A inteligência com a herança genética para Gardner (2001) vem da combinação desta com as condições de vida do indivíduo, ressaltando a relevância dos fatores genéticos e do meio ambiente, uma vez que, quanto mais estímulos o ambiente oferecer, mais competências serão desenvolvidas, minimizando a importância dos fatores genéticos.

Para Gardner, privilegiar as formas e modos de conhecer significa trabalhar com uma pedagogia centrada no compreender, na qual se deve educar para a compreensão. Muitos pontos de entrada na TIM seriam possíveis para articular o estudo em questão. Considerando que a abordagem do mesmo tem foco na docência, algumas categorias foram recortadas para a construção de um modelo conceitual, capaz de nortear as análises pretendidas.

É fato que as instituições de ensino superior encontram-se abertas para o uso das mídias digitais. Entretanto, é preciso considerar as inquietações geradas sobre como esse uso se configura e quais as implicações cognitivas são dele decorrentes. Trata-se de uma inquietação relevante, uma vez que a convergência das tecnologias digitais aponta para um mundo de possibilidades na educação, ou seja, a integração das mídias agrega valor ao processo 
educacional e a interatividade proporcionada por estas pressupõe uma atitude de vida muito mais ativa, investigativa e inovadora. Apresentamos os pontos principais de cada inteligência, segundo Gardner (2000) e estudiosos de sua Teoria como Brennand e Vasconcelos (2005) e Armstrong (2001):

Inteligência Linguística - nessa inteligência, destacamos a capacidade de usar as palavras, seja na forma oral, escrita, leitura ou escuta, na língua materna ou estrangeira. Tem, como base, os símbolos linguísticos, palavras e articulação lógica, implicando na estrutura da linguagem, a semântica e as dimensões pragmáticas, fazendo uso da linguagem de forma criativa, retórica, explicativa e mnemônica (ARMSTRONG, 2001 ; GARDNER 1995). Para Gardner (1995), o dom da linguagem é universal e pode ser encontrado em todas as culturas. Mesmo quando o indivíduo não tem a capacidade da fala e a linguagem de sinais não foi estudada, ele consegue criar sua própria forma de linguagem para se fazer entender. Trata-se da capacidade do uso da linguagem para se expressar e entender significados simples ou complexos.

Essa inteligência está fortemente presente em pessoas que têm a capacidade de usar as palavras para expressar suas ideias como, por exemplo, os escritores, jornalistas e poetas. $\bigcirc$ docente tem o importante papel no estímulo 98 do uso dessa inteligência e ações docentes; nesse sentido, são encontradas no ensino tradicional. Segundo Gardner (1995), a inteligência linguística é a mais forte entre os seres humanos. É exercida com mais facilidade e, no âmbito educacional, é estimulada em todos os níveis escolares, uma vez que a capacidade de falar e escrever bem é essencial ao processo de comunicação e, por isso mesmo, torna-se prioridade no sistema de ensino, sendo constantemente aperfeiçoada.

Inteligência Lógico-matemática - a capacidade de usar os números de forma efetiva, manifestada na solução de problemas e no desenvolvimento do raciocínio dedutivo, através de padrões e relacionamentos lógicos, ordem e sistematização, afirmações e proposições, funções e outras abstrações relacionadas, implicando na utilização do raciocínio abstrato e da organização lógica do pensamento reflete a inteligência matemática. A representação mental apresenta coerência antes mesmo da representação material. Uma descrição da inteligência lógico-matemática: 
[...] um tipo de inteligência que se revela na capacidade mental do humano de guardar, na sua memória, informações de representações de quantidade e de aplicar essas informações no cotidiano, resolvendo problemas (BRENNAND; VASCONCELOS, 2005, p. 30).

Essa inteligência começa a se desenvolver na infância através da manipulação de objetos que permitam o ordenamento e reordenamento da capacidade de investigação para estabelecer relações entre objetos matemáticos e da percepção de quantidade. A inteligência lógico-matemática desenvolve-se a partir dos objetos, é

[...] ordenando-os, reordenando-os e avaliando sua quantidade que a criança pequena adquire seu conhecimento inicial e mais fundamental sobre o domínio lógico-matemático. Deste ponto de vista preliminar, a inteligência lógico-matemática rapidamente torna-se remota do mundo dos objetos materiais (GARDNER, 1995, p. 100). inteligência:

Os critérios empíricos utilizados por Gardner relacionados para esta

Certas áreas do cérebro são mais importantes do que outras no cálculo matemático. Há idiotas sábios que realizam grandes façanhas de cálculo mesmo que continuem tragicamente deficientes na maioria das outras áreas. As crianças-prodígio, na matemática, existem em grande número. $O$ desenvolvimento desta inteligência nas crianças foi cuidadosamente documentado por Jean Piaget e outros psicólogos (GARDNER, 1995, p. 25).

Inteligência Interpessoal - aponta para a capacidade de compreensão do outro, de entender e responder, adequadamente, a humores, temperamentos, motivações e desejos de outras pessoas. Aponta, ainda, para a capacidade de liderança sobre outras pessoas, demonstrando sensibilidade às suas necessidades. Trata-se de perceber melhor o outro através de suas expressões faciais, voz e gestos e, com isso, poder influenciar pessoas numa determinada linha de pensamento e ação (ARMSTRONG, 2001). Essa inteligência pode ser facilmente percebida em professores, psicoterapeutas e políticos. Os critérios empíricos utilizados por Gardner relacionados para esta inteligência: 
Todos os indícios na pesquisa do cérebro sugerem que os lobos frontais desempenham um papel importante no conhecimento interpessoal. Um dano nesta área pode provocar profundas mudanças de personalidade, ao mesmo tempo em que não altera outras formas de resolução de problema - a pessoa geralmente 'não é a mesma' depois de um dano destes (GARDNER, 1995, p. 27).

Inteligência Intrapessoal - segundo Gardner, é a mais pessoal de todas as inteligências e pode ser percebida por meio da manifestação das demais inteligências. Aponta para a capacidade de fazer uso de seus sentimentos internos, de sua habilidade para sonhar, fantasiar, transformando-os em ideias, em soluções para problemas pessoais. A habilidade intrapessoal passa pelo processo de autoconhecimento, de reconhecimento de suas potencialidades e desejos. Trata-se também da habilidade de acreditar em si mesmo e da sua capacidade de introspecção. Para Brennand e Vasconcelos (2005), é a capacidade de perceber em seus comportamentos o desejo de conhecer a si próprio e, para isso, é capaz de refletir e aprender com seus erros e de promover mudanças em seu comportamento, beneficiando pessoas de seu convívio social. As pessoas com inteligência intrapessoal aguçada geralmente são introspectivas, 100 reservadas, possuem a habilidade para o autoconhecimento, para a indução, têm consciência de sua identidade e de seus sentimentos, conhecem seus pontos fortes e fracos, possuindo sensibilidade para a compreensão do outro. inteligência:

Os critérios empíricos utilizados por Gardner relacionados para esta

Assim como na inteligência interpessoal, os lobos frontais desempenham um papel central na mudança de personalidade. Um dano na área inferior dos lobos centrais provavelmente produzirá irritabilidade ou euforia, ao passo que um dano nas regiões mais altas provavelmente produzirá indiferença, desatenção, lentidão e apatia - um tipo de personalidade depressiva. Nestes indivíduos 'lobos-frontais', as outras funções cognitivas geralmente continuam preservadas. Em contraste, entre os afásicos que se recuperaram o suficiente para descrever suas experiências, nós encontramos um testemunho consistente: embora possa ter havido uma diminuição da atenção geral e uma considerável depressão em virtude da condição, o indivíduo de maneira nenhuma se sentia uma pessoa diferente. Ele reconhecia suas próprias necessidades, vontades e desejos e tentava atendê-los, tão bem quanto possível (GARDNER, 1995, p. 29). 
Inteligência Espacial - segundo Gardner, esta inteligência caracteriza-se pela solução de problemas como o uso do sistema notacional de mapas ou, ainda, da visualização de um objeto de um ângulo diferente (1995). Para Brennand e Vasconcelos (2005), trata-se do contato, habilitando os indivíduos a desenhar, mapear e visualizar objetos em várias dimensões, independente do contato material. A inteligência espacial traduz a capacidade que o indivíduo tem de transformar objetos, de se referenciar e de se localizar no meio em que vive. Os critérios empíricos utilizados por Gardner relacionados para esta inteligência:

As evidências da pesquisa do cérebro são claras e persuasivas. Assim como o hemisfério esquerdo, durante o curso da evolução, foi escolhido como local de processamento linguístico nas pessoas destras, o hemisfério direito é comprovadamente o local mais crucial do processamento espacial. Um dano nas regiões posteriores direitas provoca prejuízo na capacidade de encontrar o próprio caminho em torno de um lugar, de reconhecer rostos ou cenas, ou de observar detalhes pequenos. Os pacientes com danos específicos nas regiões do hemisfério direito tentarão compensar suas falhas espaciais com estratégias linguísticas. Eles tentarão raciocinar em voz alta, pôr em dúvida a tarefa ou inclusive inventar respostas. Mas essas estratégias não-espaciais raramente são bem sucedidas. As populações cegas ilustram a distinção entre a inteligência espacial e a percepção visual. Uma pessoa cega pode reconhecer formas através de um método indireto: passar a mão ao longo do objeto traduz a duração do movimento, que por sua vez é traduzida no formato do objeto. Para a pessoa cega, o sistema perceptivo da modalidade tátil equivale à modalidade visual na pessoa que enxerga. A analogia entre o raciocínio espacial do cego e o raciocínio linguístico do surdo é notável (GARDNER, 1995, p. 26).

Inteligência Corporal-cinestésica - segundo Gardner (1995), o conhecimento corporal-cinestésico satisfaz muitos dos critérios de uma inteligência por se tratar da capacidade de usar o próprio corpo para expressar uma emoção (como na dança), jogar (como num esporte) ou criar um produto. É uma evidência dos aspectos cognitivos do uso do corpo quanto à flexibilidade, equilíbrio, coordenação, velocidade, força e destreza. É a competência responsável pelo controle dos movimentos corporais, criando representações possíveis de ser executadas pelo corpo, em espaços e situações diversas (BRENNAND; 
VASCONCELOS, 2005). Os critérios empíricos utilizados por Gardner relacionados para esta inteligência:

O controle do movimento corporal está, evidentemente, localizado no córtex motor, com cada hemisfério dominante ou controlador dos movimentos corporais no lado contra lateral. Nos destros, a dominância desse movimento normalmente é encontrada no hemisfério esquerdo. A capacidade de realizar movimentos quando dirigidos para fazê-los pode estar prejudicada mesmo nos indivíduos que podem realizar os mesmos movimentos reflexivamente ou numa base voluntária. A existência de uma apraxia específica constitui uma linha de evidência de uma inteligência corporal-cinestésica (GARDNER, 1995, p. 21).

Para Gardner, esta inteligência completa a inteligência musical.

Inteligência Musical - segundo Gardner (1995), a noção de música é uma faculdade universal constante de um sistema simbólico acessível e lúdico. É a capacidade de aprender sons, ritmos, de interpretá-los e até de reconstruir novos contornos melódicos com arranjos musicais. Acerca dessa inteligência, Brennand e Vasconcelos descrevem o seguinte:

No caso da criação da música (composição), a inteligência musical desenvolve-se numa interação ambiental (natural e social) que atinge as emoções, tanto do indivíduo que compõe ou executa a música, quanto de qualquer ser vivo que a escuta (BRENNAND; VASCONCELOS, 2005, p. 311 .

A música traduz uma inteligência que pode se relacionar com outras inteligências, a exemplo das inteligências intrapessoal, interpessoal, espacial, linguística e, até mesmo, a matemática. A linguagem também pode ser beneficiada pela música, tornando-a um elemento catalizador das inteligências. E todas essas inteligências contribuem para a inteligência musical, a exemplo da necessidade do conhecimento básico em matemática para entender a função dos critérios empíricos, utilizados por Gardner relacionados para esta inteligência:

[... certas partes do cérebro desempenham papéis importantes na percepção e produção da música. Estas áreas estão caracteristicamente localizadas no hemisfério direito, embora a capacidade musical não esteja 'claramente' localizada em uma área tão 
específica como a linguagem. Embora a suscetibilidade particular da capacidade musical ao dano cerebral dependa do grau de treinamento e de outras diferenças individuais, existe uma clara evidência de 'amusia' ou perda da capacidade musical (GARDNER, 1995, p. 23).

\section{O processo de produção da aplicação interativa}

O primeiro passo para a criação da aplicação interativa pelo docente foi sua apropriação da Teoria. Os docentes participantes da pesquisa, antes da criação do conteúdo interativo, acessaram um conteúdo educativo interativo sobre a TIM. $O$ vídeo e o texto sobre a referida teoria foram produzidos para apresentar as características das inteligências de forma inovadora. Os docentes puderam, assim, ter acesso ao conteúdo sobre as características de cada inteligência conforme descrito na TIM. A partir daí, escolheram e inseriram as marcações em vídeo de acordo com as inteligências que pretendiam ativar. As âncoras hipermídias autocontidas utilizadas pela ferramenta possibilitam uma navegação pelo conteúdo, proporcionando, assim, a interatividade como um recurso pedagógico inovador.

\section{Resultados - criando interatividade}

processo de autoria docente na produção de conteúdos educativos interativos obedeceu às fases do modelo conceitual. Constituiu-se da fase de experimentação em que as docentes buscaram entender as categorias basilares da TIM, acessando o material disponibilizado pela ferramenta e buscaram identificar com que inteligências poderiam trabalhar. Apropriando-se do problema, começaram, assim, a construção da aplicação interativa. Através de pesquisa individual, buscaram conteúdos relacionados ao tema da videoaula que poderiam inserir na aplicação interativa e passaram para a fase de abstração relacionando os ícones com o conteúdo selecionado, escolhendo o tipo de mídia para associar a cada ícone, o momento da inserção do ícone, o tempo de duração de cada conteúdo interativo, estimando o tempo de permanência do ícone no vídeo original. Em nenhum momento foi oferecida às docentes uma demonstração de como a ferramenta funcionava. 
Na fase de resolução, as docentes começaram a experimentar a ferramenta inserindo os recursos interativos, culminando na aplicação construída, que validaram verificando se o resultado obtido estava de acordo com as hipóteses levantadas inicialmente. Verificados erros, novas versões eram implementadas, incluindo na ferramenta a opção para modificar ou excluir conteúdos já inseridos na aplicação e melhorando a sua interface, visando de atender melhor às exigências de usabilidade colocadas por Nielsen (2012).

Novos roteiros eram testados e construídos, e o grau de aproximação dessa validação com as previsões iniciais atestou um bom resultado. Gardner ( 1995 ) mostra que as implicações educacionais da TIM na tentativa de abranger uma grande quantidade de conteúdos e inteligências torna-se impossível. No caso desse protótipo, foi possível abordá-lo de, no mínimo, cinco maneiras diferentes. Como indicadores presentes na aplicação interativa, estabelecemos os cinco pontos de entrada conforme definidos por Gardner (1995): ponto de entrada narrativo, ponto de entrada lógico-quantitativo, ponto de entrada conceitual, ponto de entrada estético ou abordagem estética e o ponto de entrada experiencial ou abordagem experiencial. Esses indicadores foram encontrados a partir das sete categorias basilares da TIM, presentes na aplicação interativa, 104 ou seja, as aplicações interativas foram produzidas em função dessas categorias, estabelecendo pontos de entrada que irão determinar se o conteúdo tem, como proposta, ensinar para a compreensão.

A exploração do material baseou-se na transformação dos dados coletados nas aplicações interativas. Como unidades de registro dos pontos de entrada (indicadores), definimos os ícones representativos das inteligências múltiplas (ZANDOMENEGHI, 2005). Os conteúdos interativos acessados a partir dos referidos ícones foram definidos como unidades de contexto. Dessa forma, verificamos se os conteúdos acessados através dos ícones, apresentavam consistência com o ícone tornando-se um conteúdo para ativar a inteligência correspondente. Na exploração das aplicações interativas produzidas, buscamos verificar se cada uma tem, pelo menos, cinco pontos de entrada distintos. Assim, a presença de cada ponto de entrada foi contada. No tratamento dos resultados, as inferências e interpretações foram feitas a partir da fundamentação teórica e dos pressupostos que conduziram a investigação com base nas categorias basilares da TIM (GARDNER, 2000) anteriormente apresentadas.

O conteúdo de origem foi trabalhado pelo docente, tendo como foco os possíveis estímulos que o aprendente precisaria encontrar para ter as suas 
habilidades despertadas. Para isso, o conteúdo de origem foi minuciosamente estudado para que os pontos de interatividade com novos conteúdos fossem estabelecidos. Nesse sentido, Gardner explica que as inteligências são potenciais que podem ser ativados dependendo dos valores culturais do sujeito, das decisões pessoais de cada um e das oportunidades que se apresentam em sua cultura.

Observamos a facilidade com que os docentes conseguiram representar diferentes inteligências na construção da aplicação interativa. Todos os ícones selecionados representaram a interação com diferentes conteúdos. $\mathrm{Na}$ Figura 3, apresentamos a tela da aplicação, contendo um ícone representativo da inteligência linguística.

\section{Figura 3}

\section{Ícone da inteligência linguística}

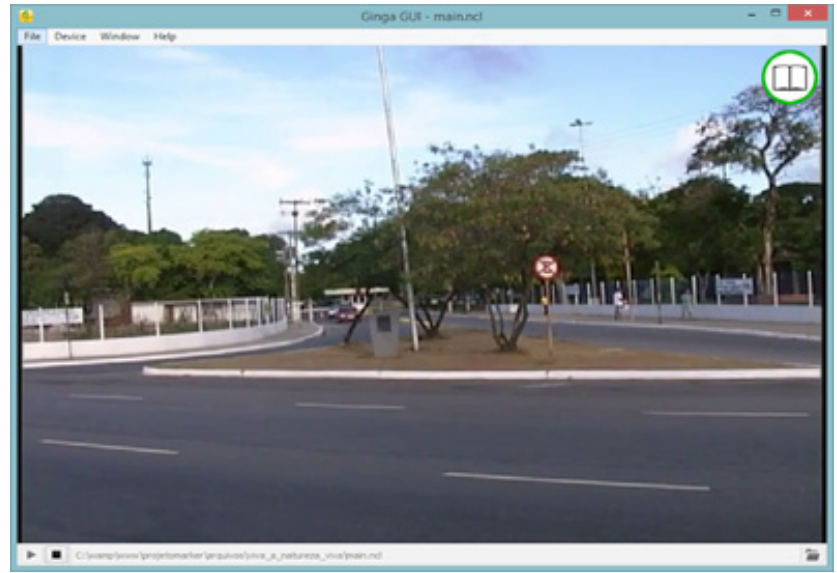

Fonte| Autores

Acionando a marcação utilizando o botão verde do controle remoto, resulta na exibição do conteúdo apresentado pela Figura 4. Após o acionamento do link inserido no ícone do globo, é exibido um QR-code no lado inferior direito da tela. 
Figura 4

Utilização de QR-code como marcação em vídeo interativo para TVD

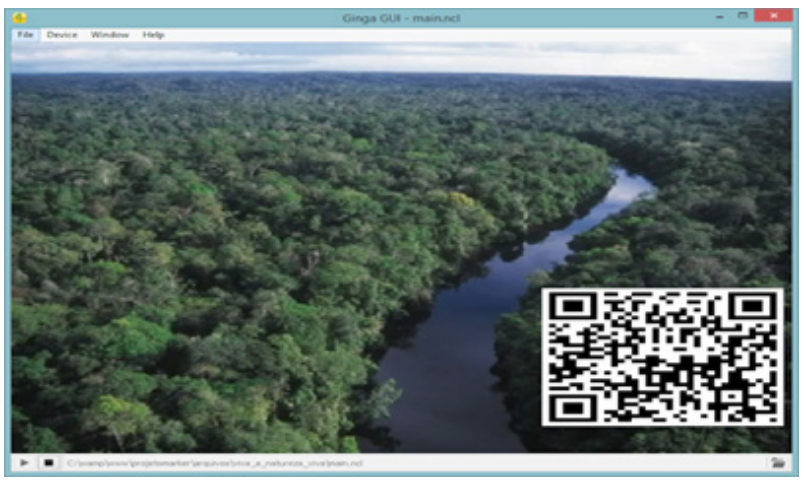

Fonte | Autores

Na Figura 5, é apresentado o ícone representativo da inteligência linguística ao aprendente.

Figura 5

Ícone representando a inteligência linguística

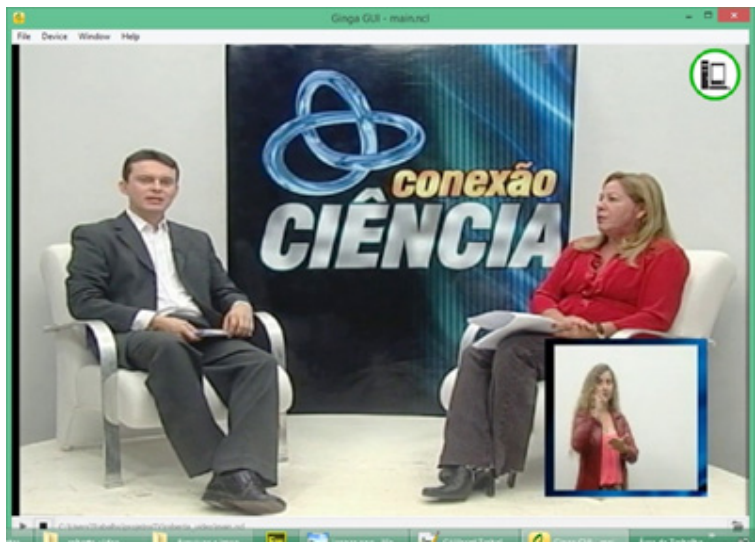

Fonte | Autores 
Figura 6

Conteúdo acionado a partir do ícone da inteligência linguística

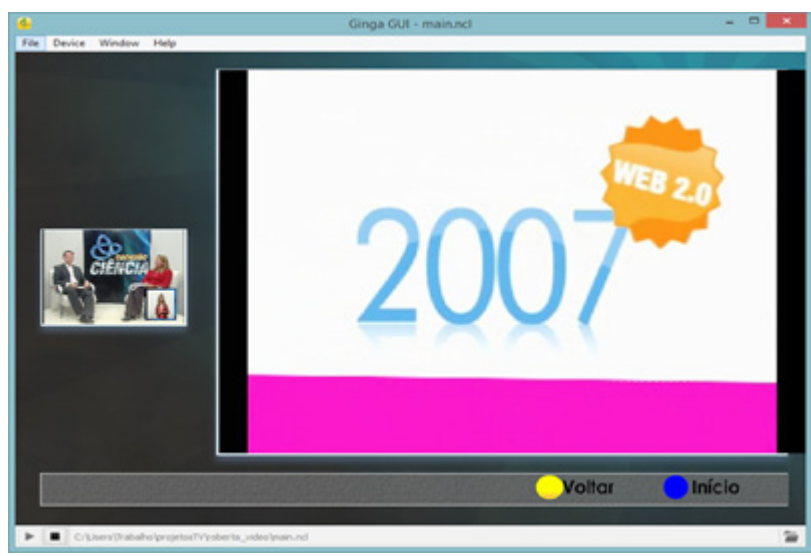

Fonte | Autores

Na Figura 7, podemos observar uma imagem da aplicação Z fazendo uso dos recursos interativos.

Figura 7

Ícone representando a inteligência musical

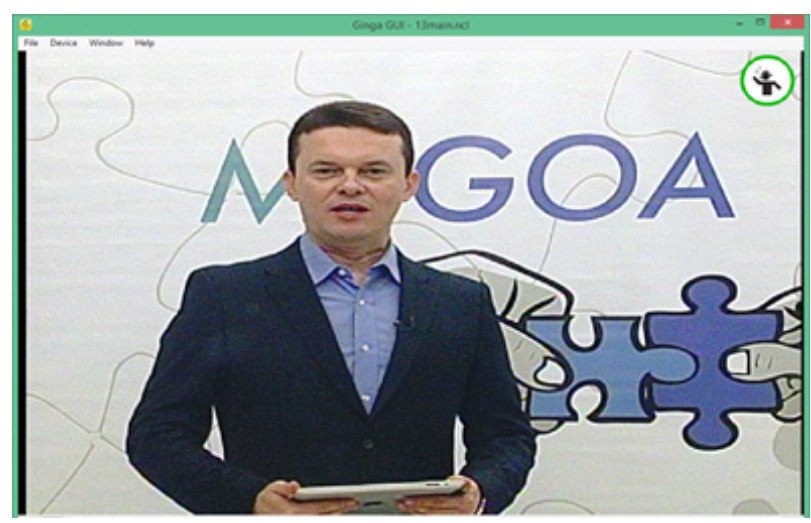

Fonte | Autores

resultado desse processo de autoria pôde ser avaliado através da aplicação de uma experiência de uso dos vídeos interativos, gerados 
em uma turma de alunos realimentando o processo de autoria docente, de aprimoramento do modelo e da própria ferramenta. Ancoramo-nos em Kapitango-A-Samba (2013), para compreender que esta pesquisa conferiu à autoria docente uma perspectiva dialógica em torno de uma experiência vivida na sua especificidade.

Consideramos importante destacar que a implementação dos testes nos permitiu problematizar a autoria docente. Para Oliveira (2010, p. 38), "[... ser autor(a) da prática pedagógica é pensar sobre o que foi feito, o que se está fazendo e o que é possível fazer, logo, as autorias pedagógicas constituir-se-ão fontes de saberes, na medida em que o(a) professor(a) formado(a) analisa, interage e reflete sobre estes". Assim, trabalhamos com um conceito de autoria docente cujos aspectos cognitivos que permeiam o processo estão refletidos em suas escolhas e sistematizações, expressando um estilo próprio. Trata-se de um processo ancorado na autonomia que se realiza a partir das relações e contradições, da crítica sobre nós mesmos, como docentes e das relações que estabelecemos uns com os outros.

$\bigcirc$ processo de autoria docente permitiu escolher caminhos dentro do conteúdo interativo que pudessem ensinar um mesmo conteúdo com, no 108 mínimo, cinco maneiras diferentes, estabelecendo pontos de entrada que representam os padrões das múltiplas inteligências, cujo conteúdo, disponível na ferramenta, orientou o docente sobre as características de cada inteligência, ajudando-o a refletir melhor sobre como potencializá-las no aprendente, como, por exemplo, considerando um determinado conteúdo, quais os momentos do vídeo com potencial para trabalhar um áudio ou um texto e que conteúdos poderiam ser agregados nesse contexto. Assim, o docente estaria trabalhando a inteligência linguística.

No caso da inteligência espacial, o docente se perguntou em que momento do vídeo ele poderia fazer uso de mapas, visualização, recursos visuais, entre outros para ajudar determinado aprendente a compreender melhor o conteúdo. Essa é uma perspectiva que pode ser constatada através da forma como Gardner (1995) organiza a sua teoria em torno da educação, numa dentro de uma perspectiva compreendendo cinco rotas ou pontos de entrada; todas elas utilizadas na implementação da interatividade dos vídeos: Narrativa: oportuniza ao aprendente uma aprendizagem através de histórias contadas ou narrativas sobre um conceito em questão; Lógico-quantitativo: oportuniza caminhos aos aprendentes de forma que respondam, com mais facilidade, a 
uma consideração de ordem numérica e de fazer uso de sua capacidade de dedução; Conceitual: oferece ao aprendente a oportunidade de fazer uso de aspectos filosóficos acerca de uma determinada temática; Estética: Esse é um caminho pelo qual o aprendente pode fazer uso de sua capacidade sensorial; Experiencial: Essa rota permite ao aprendente usar uma abordagem prática numa determinada atividade.

Para Gardner (2000), o docente, ao oferecer variadas rotas de acesso ao conhecimento para os seus aprendentes, um conteúdo que tenha como proposta ensinar para a compreensão, estará oferecendo alternativas para o entendimento de um determinado assunto, mobilizando um conjunto de inteligências diferentes. Cada indivíduo tem habilidades distintas e isso determina a diferença entre eles. Cada indivíduo aprende do seu modo pessoal e único. Para aprender, é preciso percorrer abordagens ou caminhos que cada um pode traçar para si mesmo. Segundo Brennnand e Lemos (2007), as tecnologias que permitem mais e mais interação trarão em si as possibilidades de ampliação de processos cognitivos mais amplos. Torna-se, então, uma tecnologia educativa, cujos procedimentos didáticos e pedagógicos deverão proporcionar uma aprendizagem mais dinâmica e flexível.

Para o professor, a digitalização de conteúdos permite reinventar a educação como um todo. As plataformas digitais possibilitam a combinação de conteúdos, através da manipulação de textos, imagens, som, animação, por qualquer mídia, em qualquer lugar. Dessa forma, a reprodução do mundo físico no mundo virtual promove a mobilidade, flexibilidade, liberdade de escotha e a interação com pessoas em espaços diferentes

\section{Considerações finais}

Este trabalho de pesquisa mostrou várias percepções de como é possível produzir processos de construção do conhecimento, balizados pelos estímulos à cognição humana que as tecnologias possam propiciar. Ao buscarmos desenvolver competências docentes para o uso da TIM e das mídias digitais, pudemos inferir que a formação docente em todos os níveis devem contemplar o uso de artefatos tecnológicos variados. Entendemos que a construção dos protótipos permitiu a visualização de novas oportunidades de autoria docente através do aproveitamento das potencialidades da convergência 
tecnológica que, fundamentadas numa importante teoria educacional, possibilita novos textos e contextos para a sala de aula. Gardner (1995, p. 213 ) "[...] destaca que as tecnologias podem ser desenvolvidas de modo a maximizar as chances de cada aluno aprender".

Nesse sentido, a cultura digital presente em nossa sociedade impõe à escola um planejamento didático que leve em conta o fácil acesso à informação e ao conhecimento. A competência docente para o uso das tecnologias digitais vem ao encontro do redimensionamento dos modelos educacionais vigentes e da Teoria de Gardner (2000). Nesse contexto, pensar a autoria docente fazendo o uso das tecnologias digitais requer pensar a formação docente inicial e continuada, visto que os processos educativos instituídos através dessas duas vertentes, no que diz respeito ao uso das tecnologias como um instrumento pedagógico, vão muito além de dotar o docente de conhecimento técnico na utilização desses recursos. Assim, constatamos a importância da competência digital na formação docente.

Conforme consta nos documentos oficiais que regulamentam a formação de professores com base no quadro de referência para os países da União Europeia - EU (COMISSÃO EUROPEIA, 2007), é possível identificar 110 entre as competências essenciais à competência digital, que envolve a utilização segura e crítica das tecnologias midiáticas e, portanto, as competências básicas no uso das mídias digitais. As competências essenciais para a aprendizagem, ao longo da vida, enquadram-se nos princípios de igualdade e acesso para todos, sendo fundamentais numa sociedade do conhecimento, "[...] e garantem maior flexibilidade e rápida adaptabilidade da população ativa às mudanças constantes num mundo cada vez mais interligado" ICOMISSÃO EUROPEIA, 2007, p. 31.

No Ensino Superior, os aprendentes já adquiriram as competências de base, na maioria das vezes, a competência digital. A ubiquidade, capacidade de estar presente em vários lugares ao mesmo tempo, contribui para que esses indivíduos compreendam a presença das mídias digitais em seu cotidiano. A capacidade de explorar e mobilizar recursos como conhecimentos, habilidades e atitudes num contexto particular constitui o conceito de competência de maior ocorrência em textos publicados (BEHAR, 2013; FLEURY; FLEURY, 2001 ; LE BOTERF, 2003; PERRENOUD, 2002). Para Le Boterf (2005, p. 70), a competência refere-se a um "[...] saber agir que supõe saber combinar e mobilizar 
recursos pertinentes [...] o querer agir que se refere à motivação [...] e o poder agir que remete para a existência de um contexto".

Assim, consideramos que a competência existe quando é demonstrada, ou seja, quando a pessoa é capaz de aplicar as suas aptidões ou habilidades numa atividade. Ademais a competência é uma disposição para agir de modo pertinente em relação a uma situação específica (LE BOTERF, 2003). A competência implicou saber coordenar operações e não somente aplicá-las isoladamente. Requer uma instrumentalização em saberes e capacidades, mas não se reduz a essa instrumentalização. A competência envolve a capacidade de integrar saberes múltiplos e heterogêneos para a realização de uma atividade.

docente na educação superior precisa lançar mão de alternativas para inovação de seu cotidiano no sentido de favorecer autonomia do aprendente na busca de conhecimento e de desenvolvimento de suas múltiplas inteligências. Alguns aspectos da TIM podem ajudar nessa discussão, pois consideram a dinâmica entre os indivíduos e a sociedade onde estão inseridos, seus múltiplos contextos e como esses contextos simultaneamente requerem e estimulam diferentes arranjos e grupos de inteligência. Considerar esses aspectos enquanto pensamos numa educação de qualidade, com currículos inovadores, é perceber a escola centrada no indivíduo, em suas capacidades e tendências, de forma a trazer para a discussão a necessidade de adequar o indivíduo a uma forma diferenciada de aprendizagem.

Reconhecemos as limitações do estudo, considerando o número pequeno de vídeos trabalhados, bem como o grupo de docentes participantes da investigação, mas entendemos sua importância como experiência que poderá fomentar outros estudos e debates sobre o desenvolvimento das competências digitais para o exercício da docência, sobretudo no ensino superior.

\section{Referências}

ALMEIDA, Maria Elizabeth Bianconcini de; BRENNAND, Edna Gusmão de Goés. A educação a distância na era da sociedade em rede. In: BRENNAND, Edna Gusmão de Góes; ALBUQUERQUE, Maria Elizabeth Baltar Carneiro de. Formação docente e tecnologias digitais. João Pessoa: Editora UFPB, 2011 
ARMSTRONG, Thomas. Inteligências múltiplas na sala de aula. Tradução Maria Adriana Veríssimo Veronese. Porto Alegre: Artmed, 2001.

BEHAR, Patrícia Alejandra. Competências em educação a distância. Porto Alegre: Penso, 2013.

BORGES, Leonidas Leão. Múltiplas inteligências, criação e interatividade no ambiente virtual de aprendizagem edulivre. 2010. 22 1f. Tese (Doutorado em Educação) - Programa de Pós-Graduação em Educação, Universidade Federal da Paraíba, João Pessoa, 2010.

BRENNAND, Edna Gusmão de Góes; VASCONCELOS, Giuliana Cavalcanti. O Conceito de potencial múltiplo da inteligência de Howard Gardner para pensar dispositivos pedagógicos multimidiáticos. Ciências \& Cogniç̣ão, Rio de Janeiro, v. 2, n. 5, p. 19-35, 2005. Disponível em: <www.cienciasecognicao.org>. Acesso em: 20 maio 2010.

COMISSÃO EUROPEIA. Competências essenciais para a aprendizagem ao longo da vida. Luxemburgo: Serviço das Publicações Oficiais das Comunidades Europeias, 2007. Disponível em: http://ec.europa.eu/dgs/education_culture/publ/educ-training_en.html. Acesso em: 15 mar. 2013.

FLEURY, Afonso; FLEURY, Maria Teresa Leme. Construindo o conceito de competências. RAC 112 Curitiba, v. 5, p. 183-196, 2001.

FREIRE, Paulo. Extensão ou comunicação. Rio de Janeiro: Paz e Terra, 1985.

GARDNER, Howard. Estruturas da mente: a teoria das Inteligências Múltiplas. Tradução Sandra Costa. 2. ed. Porto Alegre: Artmed, 2000.

Inteligências múltiplas: a teoria na prática. Tradução Maria Adriana Véronesee. Porto Alegre: Artmed, 1995.

Inteligência: um conceito reformulado. Tradução Adalgisa Campos da Silva. Rio de Janeiro: Objetiva, 2001.

A nova ciência da mente: uma história da revolução cognitiva. Tradução Cláudia Malbergier Caon. São Paulo: Editora da Universidade de São Paulo, 2003.

KAPITANGO-A-SAMBA, Kilwangy Kya. Autoria com ética: reflexões sobre problemas éticos no processo autoral. Revista de Estudos Sociais, Cuiabá, v. 15, n. 30, p. 93 -104. 2013.

LE BOTERF, Guy. Desenvolvendo as competências dos profissionais. Porto Alegre: Artmed, 2003. 
LE BOTERF, Guy. Construir as competências individuais e colectivas. Porto: Edições Asa. 2005.

LEFFA, Vilson José. Uma ferramenta de autoria para o professor: o que é e o que faz. Letras de Hoje, Porto Alegre, v. 41, n. 144, p. 189-214, 2006.

LÉVY, Pierre. As tecnologias da inteligência: o futuro do pensamento na era da informática. Tradução Carlos Irineu da Costa. Rio de Janeiro: Editora 34, 1997.

A inteligência coletiva: por uma antropologia do ciberespaço. Tradução Luis Paulo Rouanet. 5. ed. São Paulo: Loyola, 1998.

NIELSEN, Jakob. Usabilty engineering. San Francisco: Morgan Kaufmann, 1993.

OLIVEIRA, Stella Maria Lima Gaspar. Tecendo reencantamentos do desvelar de professores(as) tecelãs de autorias. 2010. $210 f$. Tese de Doutorado. (Programa de PósGraduação em Educação) - Programa de Pós-Graduação em Educação, Universidade Federal da Paraíba, João Pessoa, 2010.

PERRENOUD, Phillippe. As competências para ensinar no século XXI. A formação dos professores e o desafio da avaliação. Porto Alegre: Artmed, 2002.

PRETTO, Nelson. Uma escola sem/com futuro: educação e multimídia. 7. ed. Campinas: Papirus, 2009.

ZANDOMENEGHI, Ana Lúcia Alexandre de Oliveira. Ícones representativos das inteligências múltiplas. 2005. 207f. Tese. (Doutorado em Engenharia da Produção) - Universidade Federal de Santa Catarina, Florianópolis, 2005.

Profa. Dra. Ismênia Mangueira Soares Universidade Federal da Paraíba | João Pessoa Escola Técnica de Saúde do Centro de Saúde Programa de Pós-Graduação em Educação Grupo de Pesquisa Cultura Digital e Educação E-mail |ismamangueira@gmail.com 
Profa. Dra. Edna Gusmão de Góes Brennand Universidade Federal da Paraíba | João Pessoa Centro de Educação Programa de Pós-Graduação em Educação Grupo de Pesquisa Cultura Digital e Educação Programa de Pós-Graduação em Gestão nas Organizações Aprendentes E-mail | ebrenna2@uol.com.br

Recebido 27 jun. 2016 Aceito 24 jul. 2016 